\title{
Research on Drilling Rate Optimization of a UCS Identification System While Drilling for Coal Mine Roadway Roofs
}

\author{
Guangdong Yu, Qian Hu *, Xuewen Feng, Guoying Meng and Yifan Nie
}

Citation: Yu, G.; Hu, Q.; Feng, X.; Meng, G.; Nie, Y. Research on Drilling Rate Optimization of a UCS Identification System While Drilling for Coal Mine Roadway Roofs. Machines 2021, 9, 242. https:// doi.org/10.3390/machines 9100242

Academic Editors: Pavlo Krot and Radosław Zimroz

Received: 6 September 2021 Accepted: 13 October 2021 Published: 18 October 2021

Publisher's Note: MDPI stays neutral with regard to jurisdictional claims in published maps and institutional affiliations.

Copyright: (c) 2021 by the authors. Licensee MDPI, Basel, Switzerland. This article is an open access article distributed under the terms and conditions of the Creative Commons Attribution (CC BY) license (https:/ / creativecommons.org/licenses/by/ $4.0 /)$.
School of Mechatronics and Information Engineering, China University of Mining and Technology, Beijing 100083, China; bqt1700401017@student.cumtb.edu.cn (G.Y.); fxw@student.cumtb.edu.cn (X.F.); mgy@cumtb.edu.cn (G.M.); 18855175309@163.com (Y.N.)

* Correspondence: hu949569541@163.com; Tel.: +86-185-1563-8005

\begin{abstract}
In this paper, to identify the roof unconfined compressive strength (UCS) in the process of coal mine roadway support in real-time and optimize the real-time drilling speed while drilling, this paper proposes and establishes a drilling test method for assessing the uniaxial compressive strength (UCS) of a roof. This method can be used to optimize the speed of drilling. Moreover, a mathematical model of the power output is developed for a roof-strata identification system with a drilling test system. The results were as follows: (1) the system was able to identify the uniaxial compressive strength of roof rock; (2) the pressure of the drill leg of the pneumatic bolt did not match the output power of the pneumatic motor, the pneumatic motor could not reach the maximum power point, and the insufficient thrust of the pneumatic leg led to failure of the maximum output power of the pneumatic motor; (3) to increase the output power of the air motor and thus improve the drilling speed, we applied a booster valve for the system. The experimental results show that the power of the air motor has a linear relationship with drilling speed. In this way, the speed of the drill can be increased by increasing the motor power.
\end{abstract}

Keywords: roof rock layer; pneumatic; identification while drilling; uniaxial compressive strength; pressure increasing valve; drilling rate

\section{Introduction}

Coal mine roadways are not only important living environments for underground workers but also provide paths for mineral lifting, transmission, drainage, ventilation, and mining machinery excavations [1]. Moreover, bolt supports have an important impact on coal mining. Due to their ability to strengthen the surrounding rock and their low cost, bolt supports can accelerate the speed of roadway formation, improve labor intensity and the working environment, and make coal mining more efficient with a higher yield. Bolt support has thus become the main type of support form in all countries, especially in developed countries such as Australia, the United States, and Britain [2].

The roof of a coal roadway is composed of a sedimentary layered rock mass, and the lithology of each layer is different. Most of these roof rocks are sandstone, siltstone, sandy mudstone, mudstone, sandy shale, and limestone, and the unconfined compressive strength of each layer is very different [3]. The drilling process for roof anchor holes is sometimes fast and sometimes slow, the efficiency of drilling is not high [4]. Drilling speed not only affects the speed and efficiency of hole formation, for the anchoring hole, but also has an important influence on the construction management and project schedule of the coal roadway [5]. There are many factors affecting variations in the drilling speed of the bolt drill; these factors are related not only to drilling parameters such as thrust, propulsion speed, torque, and rotation speed but also to the unconfined compressive strength of the roof rock [6].

As early as the 1950s, scholars of the former Soviet Union applied the DIRECT current method to detect the small structure of a coal seam and evaluate the stability of a roof. 
In 1965, Teale first put forward the concept of using specific techniques for drilling and crushing rock [7]. In this method, the energy consumed per unit volume by crushing rock is used to establish a mathematical model connecting the drilling parameters and formation characteristics, based on drilling parameters such as thrust, propulsion speed, torque, and rotation speed. Drilling process monitoring technology (MWD) provides improved measurements over drilling technology based on earlier drilling parameter recording technology in the field of oil drilling. MWD is usually used to measure, monitor, and record the drilling parameters of a drill. In the 1970s, foreign companies developed several systems, including Analogue Drilling Parameters (ADP) and Automated Drill Monitors (ADM). Using microprocessor-based drilling-process monitoring technology, the formations were identified, and the blasting parameters were optimized using the drilling parameters. Tiryaki and Dikmen [8], Christine N, and Beattie M noted an obvious correlation between the specific work of rock crushing and the uniaxial compressive strength index of the rock. Some scholars have $[9,10]$ noted that different rock strata have different petrological, physical, and mechanical properties when drilling the anchoring hole, and their drilling vibration characteristics are also different. Therefore, rock strata can be identified based on the vibration characteristics during drilling. Another group of scholars proposed a method for predicting rock uniaxial compressive strength based on the P-wave modulus [11]. Tan Zhuo-ying proposed a new concept that uses the perforation rate per unit of energy as the drillability [12]. Based on the coupling relationship between the effective axial pressure, rotational speed, perforation rate, and drillability during drilling, continuous layer judgments along the borehole section can be realized. Chen Jia-sheng et al. [13] determined a drilling parameter calculation formula for roof rock during drilling by detecting the pressure and flow rate of the hydraulic system of a bolt drilling machine to detect roadway roof rock. Li Xintao et al. developed concrete test blocks with different strength ratios, tested the drilling parameters of a hydraulic anchor drill, and obtained a high linear relationship between the specific work of rock crushing and the uniaxial compressive strength of concrete [14-16].

To summarize, in field rock identification [17], significant work has been done, including the use of a hydraulic anchor drill for drilling-rock identification [18], adopting a hydraulic jump bolter hydraulic motor, and using the leg flow and pressure of the hydraulic cylinder, multiplied by the efficiency of the hydraulic system, for drilling rock fragmentation. The shortcomings of the current methods include the hydraulic motor and the leg. Moreover, the efficiency of the hydraulic cylinder is difficult to measure and can only be based on experience when estimating a value. Further, the hydraulic system runs at a high temperature. Thus, efficient temperature changes will produce significant volatility, and calculating errors can lead to crushed rock [19]. At the same time, the drilling efficiency of the roof anchoring hole is not high, and research on optimization of the drilling speed has not been mentioned in the literature [20]. While drilling is used, in this paper, to identify the unconfined compressive strength (UCS) system of coal-mine roadway roof rock to overcome the shortcomings of the hydraulic system, at the same time, for the real-time identification of the roof rock's unconfined compressive strength (UCS) during drilling, the method of combining the pneumatic anchor drilling machine motor power characteristic curve can be used to optimize the jump bolter drilling speed.

The second part of the article describes the principle of mechanical specific energy. In the third part, it is found that the maximum power output of the pneumatic motor is related to the unconfined compressive strength and outrigger pressure of different rocks. The outrigger pressure of the pneumatic roof bolter does not match the output power of the pneumatic motor, so the pneumatic motor cannot reach the maximum power point. Due to the insufficient thrust of the pneumatic outrigger, the output power of the pneumatic motor cannot reach the maximum, and the pressure of the hard rock outrigger is more insufficient than that of the soft rock outrigger. In order to improve the output power of the pneumatic motor, and improve the ROP (rate of penetration), the pressurization valve is designed and installed in the system. Through testing the ROP, it is found that the power of 
the pneumatic motor has a linear relationship with the ROP, which proves that increasing the motor power can improve the effectiveness of the ROP method. The fourth part is the systematic design and experimental research of the drilling identification method of soft rock interlayer, in a coal mine roadway roof, based on drilling specific work.

\section{Research on Identification Method for the Roof-Strata Detector}

According to Teale, the mechanical specific energy is defined as the energy required to remove a unit volume of rock. The specific process can be expressed as follows:

$$
E_{s}=\frac{F}{A}+\frac{T \omega}{A_{Z}}
$$

where $E_{s}$ is the specific energy, $F$ is the thrust, $T$ is the torque, $\omega$ is the rotation speed of the drill bit when drilling, $A$ is the location, and the effective cross-sectional area refers to the ring formed by the outer radius and inner radius of the bit. $A_{Z}$ is the cross-sectional area of the bit.

\section{Optimization of Drilling Speed}

\subsection{Mathematical Model of the Output Torque of the Pneumatic Motor}

The gear motor drives the gear to spin and generate torque under high-pressure compressed air. While the motor rotor is rotating, other processes occur, including the driving moment of the motor rotor, the viscous friction moment between the end face of the gear rotor and the case, the viscous friction moment between the tooth tip of the gear rotor and the case, and the relative sliding friction moment in the meshing of the gear rotor. When the motor is idling, the torque is balanced through the friction generated by the gear rotor. When the motor drives the external load, the speed decreases, and the sum of the external load and friction force becomes balanced with the driving torque.

\subsubsection{Driving Torque of the Motor Rotor}

The force of high-pressure compressed air on the gear rotor can be expressed as

$$
F_{1}=P \cdot B \cdot\left(R-A_{1}\right)
$$

where $P$ is the air pressure; $B$ is the width of the gear rotor; $R$ is the addendum circle radius of the gear rotor; $A_{1}$ and $A_{2}$ are, respectively, the distance between the meshing point of the gear rotor and the center, $\mathrm{O}_{1}$ and $\mathrm{O}_{2}$, of the gear rotor:

$$
F_{2}=P \cdot B \cdot\left(R-A_{2}\right)
$$

The driving torque of the motor rotor $T_{0}$ is given as

$$
T_{0}=T_{1}+T_{2}=F_{1}\left[A_{1}+\frac{\left(R-A_{1}\right)}{2}\right]+F_{2}\left[A_{2}+\frac{\left(R-A_{2}\right)}{2}\right]
$$

A different arrangement of Equation (4) can be obtained as follows:

$$
T_{0}=P \cdot B \cdot\left(R^{2}-\frac{1}{2} A_{1}^{2}-\frac{1}{2} A_{2}^{2}\right)
$$


3.1.2. The Moment of Viscous Friction between the End Face of the Gear Rotor and the Housing

There is a gap between the gear end face and the housing. This gap is filled with lubricating oil. The moment of viscous friction between the end face of a single gear rotor and the housing $T_{11}$ can be expressed as:

$$
T_{11}=\frac{2 \pi \eta \omega}{\delta_{1}} \int_{R_{1}}^{R} r^{3} d r=\frac{\pi}{2} \frac{\eta \omega}{\delta_{1}}\left(R^{4}-R_{1}^{4}\right)
$$

where $\eta$ is the dynamic viscosity coefficient of the motor lubricating oil, $\delta_{1}$ is the end clearance between the gear rotor and the housing, $\omega$ is the rotation angular velocity of the gear rotor, and $R_{1}$ is the shaft journal radius of the gear rotor.

\subsubsection{Moment of Viscous Friction between the Gear and the Housing}

The torque of viscous frictional resistance in the relative motion between the gear top and the housing $T_{12}$ can be calculated as follows:

$$
T_{12}=\eta A_{2} \frac{\omega R}{\delta_{2}} \frac{R+R_{2}}{2}=\frac{\eta \omega R L_{1} B\left(R+R_{2}\right)}{2 \delta_{2}}
$$

where $L_{1}$ is the tip thickness of a single gear of the gear rotor, $\delta_{2}$ is the clearance between the gear rotor and the side of the housing, $R_{2}$ is the motor housing radius, and $A_{2}=B L_{1}$ is the addendum area of a single gear.

\subsubsection{Friction Torque Caused by Bearing Friction against the Gear Rotor}

The bearing in a geared pneumatic motor is a ball bearing, and the friction torque generated by each bearing on the gear rotor $T_{13}$ can be expressed as:

$$
T_{13}=\frac{\mu^{\prime} F^{\prime} d^{\prime}}{2}
$$

where $\mu^{\prime}$ is the coefficient of bearing friction, with $\mu^{\prime}=0.0015 \sim 0.0022 ; F^{\prime}=0.75 P \cdot B \cdot R$ is the radial thrust produced by the pneumatic action of the gear rotor on the bearing; $d^{\prime}$ is the inner diameter of the bearing.

In addition, the relative sliding friction moments of gear-rotor meshing are as follows: $f_{1}=N_{1} \mu_{1}, f_{2}=N_{2} \mu_{2}$, where $\mu_{1}$ and $\mu_{2}$ are the sliding friction coefficients of the meshing points of the two gear rotors and $N_{1}$ and $N_{2}$ refer to the positive pressure of the meshing points during the meshing of the two gear rotors. Here, $\mu_{1}=\mu_{2}=0.01415$. Because the friction coefficient is very small, it has little effect on the output torque of the motor and can be ignored.

The output torque of the pinion type pneumatic motor is given as follows:

$$
T_{M}=T_{0}-4 T_{11}-2 n_{2} T_{12}-4 T_{13}
$$

where $n_{2}$ is the number of teeth acting as seals between a single gear rotor and the inner wall of the housing.

\subsection{Mathematical Model of the Drilling Power Output}

The energy generated by the second moment in Formula (5) is 10-200 times greater than the energy generated by the first force [21]. That is, the energy generated by the torque is the main part of the drilling energy. Therefore, according to [22], the energy generated by thrust can be ignored, and the following formula can be obtained:

$$
E=\frac{T_{M} \omega_{M}}{u A_{Z}}
$$


where $A_{Z}$ is the cross-sectional area of the bit, which is a fixed value. When the UCS of the rock drilled by the bit is constant, the speed of bolt drilling $u$ is proportional to the power output by the pneumatic motor $T_{M} \omega_{M}$. Therefore, when the output power of the pneumatic motor $T_{M} \omega_{M}$ is maximum, the bolt drilling speed $\mathrm{u}$ is also maximum:

$$
\begin{gathered}
\Delta E_{2}=T_{M} \omega_{M} \Delta t \\
\Delta E_{2}=\left[P \cdot B \cdot\left(R^{2}-\frac{1}{2} A_{1}^{2}-\frac{1}{2} A_{2}^{2}\right) \cdot \omega_{M} \cdot \Delta t-2 \pi \frac{\eta \omega}{\delta_{1}}\left(R^{4}-R_{1}^{4}\right) \cdot \omega_{M} \cdot \Delta t\right. \\
\left.-\frac{2 \mu \omega R L_{1} B\left(R+R_{2}\right)}{\delta_{2}} \cdot \omega_{M} \cdot \Delta t-1.5 \mu^{\prime} P \cdot B \cdot R d^{\prime}\right] \cdot \omega_{M} \cdot \Delta t
\end{gathered}
$$

\subsection{Optimization of Drilling Speed}

When drilling with an anchor rod, the goal is to drill as fast as possible, which will not only improve the workers' labor efficiency but also reduce the production costs of the coal mine. A traditional pneumatic bolt machine is manually operated when drilling, and the drilling speed completely depends on the workers' experience. Without theoretical support, the drilling speed cannot be optimized.

The power characteristic curve of the pneumatic motor of a traditional pneumatic anchor drill is shown in Figure 1. Here, the power output by the pneumatic motor passes through the origin parabola. When the loading torque is too large, the speed of the pneumatic motor of the bolt drill reaches the minimum of zero, and then, the power output by the motor is zero. When the loading moment is zero, the power output by the pneumatic motor is also zero. At this point, the speed output by the pneumatic motor is maximum.

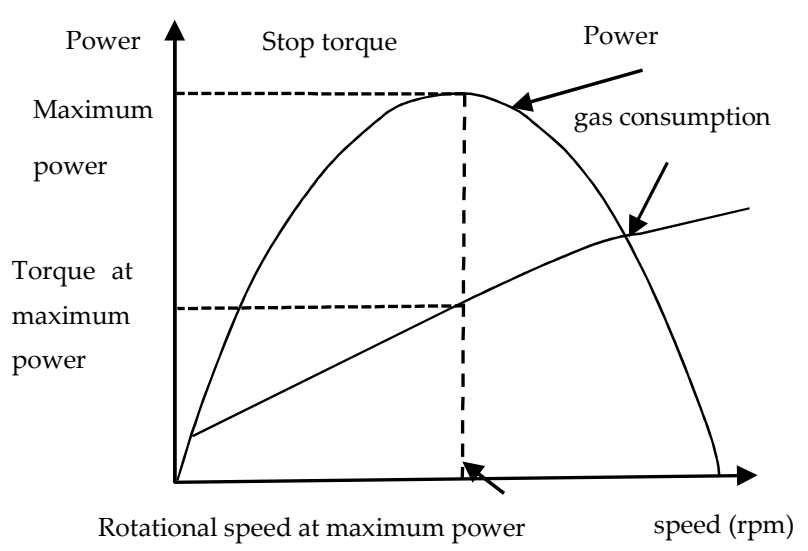

Figure 1. Power characteristic curve of the pneumatic motor.

We observed that, when the motor load torque has a certain value, the output speed of the motor is half of its maximum speed, and the motor output power is the largest. Therefore, the power output of the pneumatic motor can be maximized by using the power characteristic curve of the pneumatic motor. According to Formula (10), the drilling speed output by the bolt drilling machine is also maximum.

For example, the structural parameters of gear motor and gear rotor are the number of teeth $z=9$, modulus $M=5$, center distance $O_{1} O_{2}=49 \mathrm{~mm}, r=29.5 \mathrm{~mm}, B=70 \mathrm{~mm}$, $R_{1}=14.5 \mathrm{~mm}, \delta_{1}=0.05 \mathrm{~mm}, \delta_{2}=0.03 \mathrm{~mm}, Z_{1}=5$, the calculated average value of a is $22.765 \mathrm{~mm}$, and the average value of $B$ is $22.721 \mathrm{~mm}$. When the inlet pressure $P=0.5 \mathrm{MPa}$, $\eta=0.0267$ PAs, the calculated average torque is: $M=12.326-0.0078 \omega$.

The calculated average power is:

$$
P=M * \omega=12.326 \omega-0.0078 \omega^{2}
$$

The power curve is shown in Figure 2, which is a parabola. 


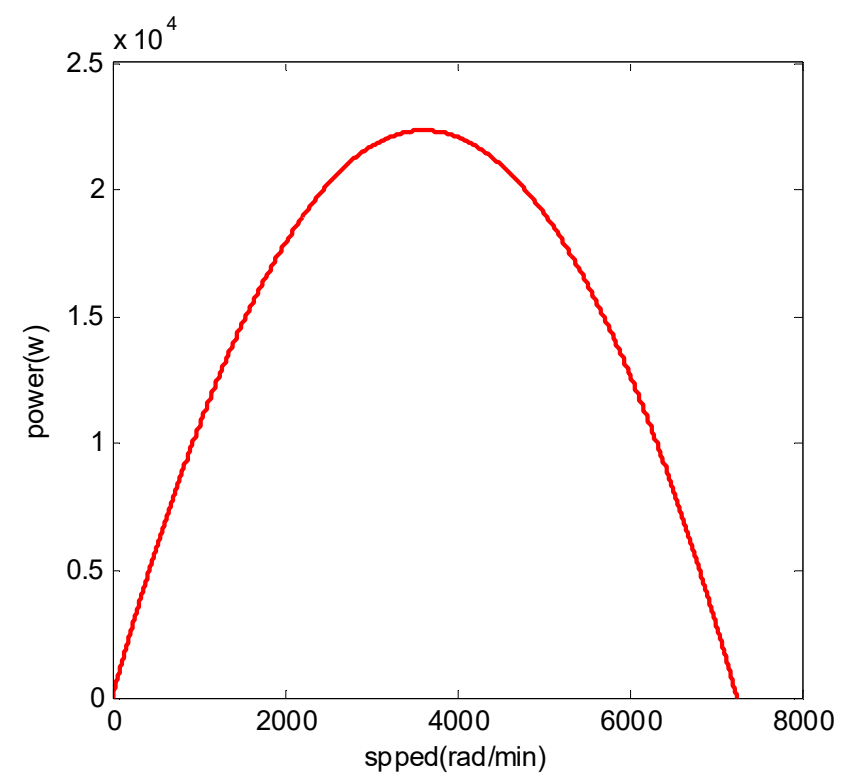

Figure 2. Speed and power curve of motor gear.

\section{Development of the UCS Detector Test System for the Roadway Rock}

\subsection{Structure and Composition of the Roof-Strata Detector}

In the process of drilling, the roof bolt hole is drilled from bottom to top in the coal mine roadway. The rock debris produced in the process of drilling is discharged from the gap between the drill pipe and the borehole wall under the action of gravity and water pressure. Thus, the energy consumption of the secondary crushing of rock debris is very small and can be ignored [23]. During drilling, the mechanical energy of the pneumatic roof bolter is converted into the heat energy of the bit and rock, which is also ignored [24,25].

When the bit drills into the roof rock, the act of drilling is divided into two kinds of motion: linear motion and rotational motion. The energy consumed is also divided into the energy consumed by the linear motion of the bit and the energy consumed by rotational motion, which refers to the drilling parameters such as bit thrust, propulsion speed, movement speed, and rotational speed. We can use Formula (1) to calculate the energy consumed by the drilling of the bit per unit volume of rock and then obtain the specific work of rock fragmentation, thereby obtaining the UCS of the roof rock.

A three-dimensional structural diagram of the rock-unconfined compressive-strength detector for roadway roof identification, proposed in this paper, is shown in Figure 3. This detector includes torque and speed sensors, displacement sensors, force sensors, pneumatic bolt machines, PDC bits, couplings, drill pipes, and controllers. The two ends of the torque and speed integrated sensor are cylindrical shafts connected to the main shaft and drill pipe of the pneumatic anchor drill through the coupling. An axle strain gauge is affixed to the inner shaft of the torque and speed sensor. A conditioning circuit is installed inside the jacket, and a base is installed outside the jacket. The base is connected to the body of the bolt machine through an iron block, as shown in Figure 4. 


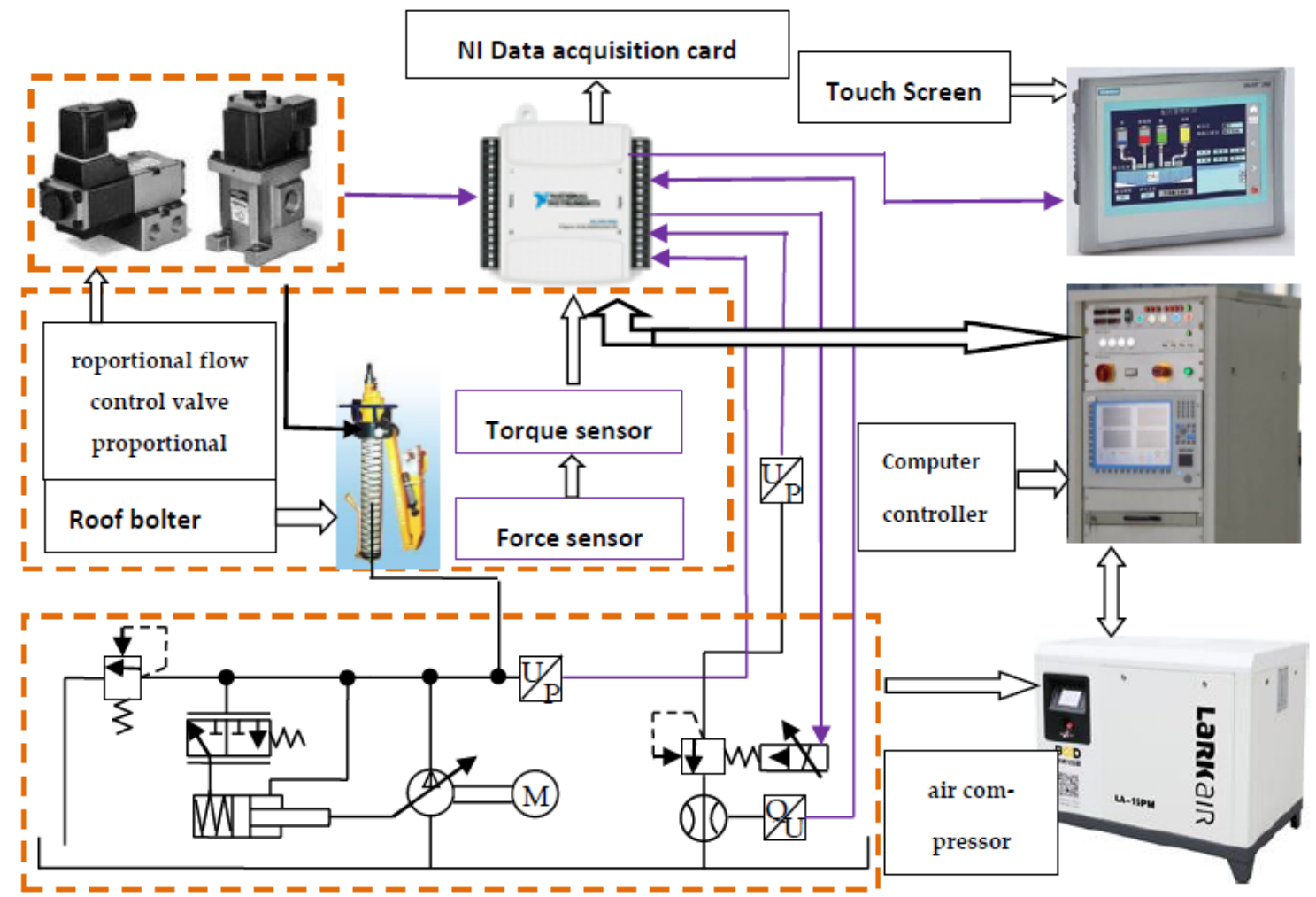

Figure 3. Experimental system of the UCS detector for roadway rock.

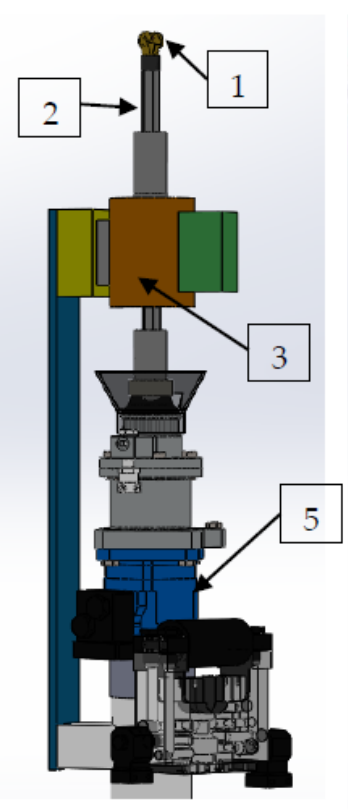

the top half

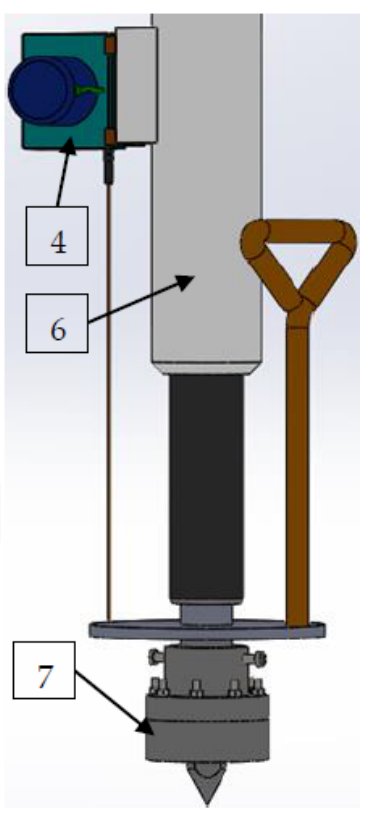

the bottom half

Figure 4. The three-dimensional structure diagram of the UCS detector of roadway rock. 1. PDC bit, 2. Drill pipe, 3. Torque and speed integrated sensor, 4. Pull rope displacement sensor, 5. pneumatic motor, 6. Pneumatic leg, 7. Force sensor.

One end of the displacement sensor is connected to the fuselage of the bolt drill, and the other end is connected to the end of the bolt machine's leg cylinder. The torque and speed sensors measure the torque of the bit against the roof rock during the drilling 
process of the pneumatic anchor drill and measure the rotation speed of the bit. The force sensor measures the pressure of the bit when drilling the rock. The displacement sensor measures the bit displacement, which can be differentiated to obtain the drilling rate. These parameters are passed to the processor, and according to these drilling parameters, the processor can obtain the UCS in the roadway roof rock stratum in real time when the roadway rock stratum is drilled.

\subsection{Experimental System for the UCS Detector of the Roadway Rock}

According to the principles of the UCS detector for roadway rock structures, outlined in Figure 4, we built a physical unconfined compressive-strength detector for roadway rock. The actual application method of vertical drilling for a coal mine roadway with a pneumatic bolt machine is shown in Figure 5. To facilitate observation, safety, and convenience, a pneumatic bolt machine was used for transverse drilling during the experiment. The experimental unconfined compressive-strength detector system for roadway rock, used during the process of transverse drilling, is shown in Figure 5, and its structure is shown in Figure 6. The test device includes three parts: the pneumatic bolt machine, the measurement- and control-system, and the compressed-air source.

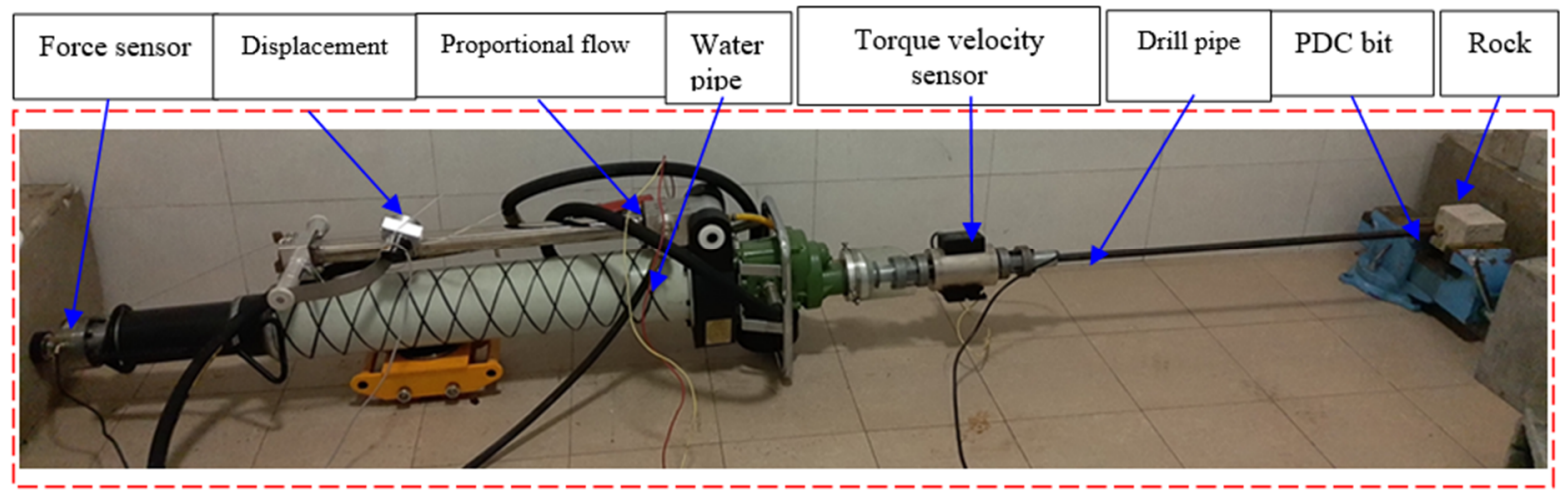

Figure 5. A structural diagram of the unconfined compressive-strength detector test system for roadway rock.

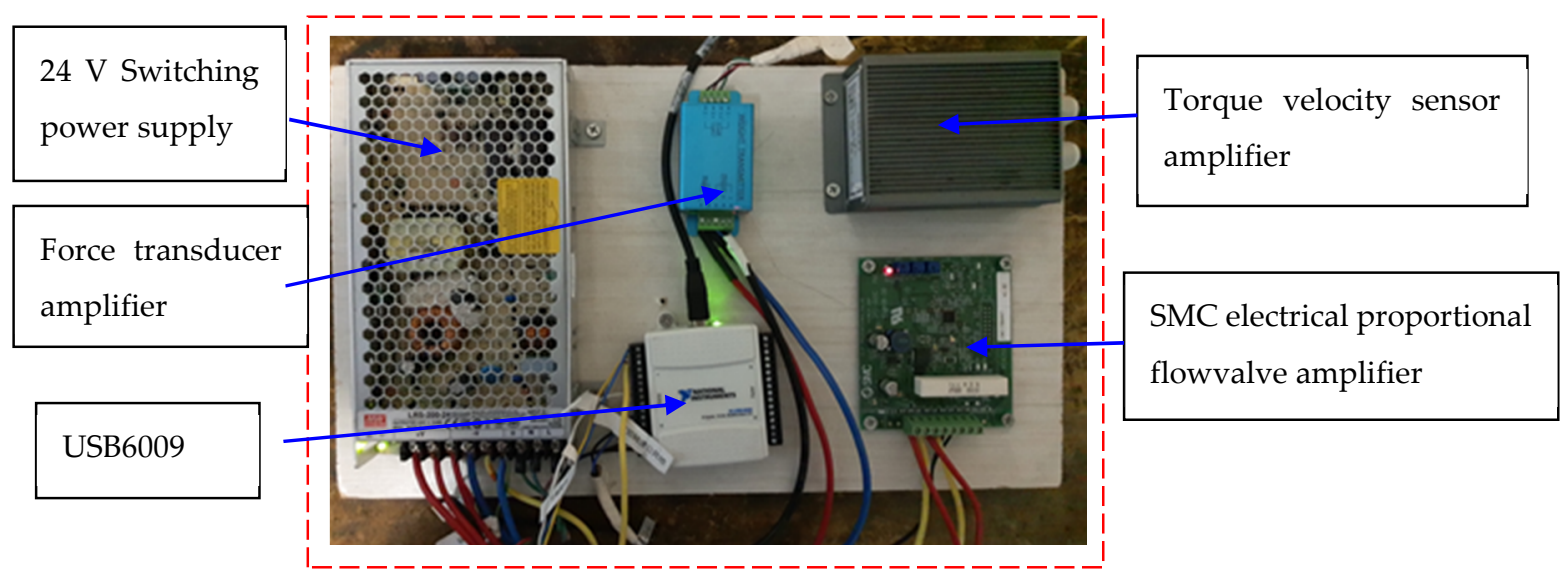

Figure 6. Hardware diagram of the unconfined compressive-strength detector test system for roadway rock.

The pneumatic bolt-machine part includes the following:

(1) A single pneumatic bolt drill;

(2) An HCNJ-101 integrated torque and speed sensor;

(3) A DYLF-102 Spoke-type force transducer;

(4) An MPS-S $1.5 \mathrm{~m}$ displacement sensor;

(5) A B19 bolt six-sided hollow drill pipe;

(6) A $\Phi 28 \mathrm{~mm}$ PDC; 
(7) A $\Phi 10 \mathrm{~mm}$ water-supply line;

(8) An SMC proportional flow valve;

(9) Rock.

The measurement and control system includes the following:

(1) An NI USB-6009 data-acquisition card and the LABVIEW software;

(2) A 24 V DC-stabilized voltage supply;

(3) A force transducer amplifier;

(4) A torque and speed integrated sensor amplifier;

(5) An SMC electric proportional flow valve amplifier.

The compressed air source includes the following:

(1) An air compressor $\left(3.8 \mathrm{~m}^{3} / \mathrm{min}\right)$;

(2) An air-storage tank;

(3) A drying machine;

(4) A filter;

(5) A reducing valve.

The experimental system is connected to high-pressure water, to scour the cuttings and cool down the PDC bit, in an effort to more realistically simulate the support situation of a roadway in a coal mine. This system is equipped with an SMC electric proportional flow valve and a valve-matching amplifier, allowing the computer to automatically control the size of the system's valve opening, automatically control the size of the pneumatic motor's rotation speed, achieve remote automatic control, and ensure convenient and safe operation. Due to the need for multi-channel data acquisition, the system also needs an electric proportional valve to control the signal output. Because of its simple structure, light weight, high precision, good reproducibility, and high responsivity, the USB6009 data acquisition card is used in this system for data acquisition and control. The LabVIEW software can also be used. The graphical programming language of this system has many controls that can be invoked. These controls are simple, fast, very reliable, and seamlessly connected with the USB 6009 data acquisition card. The specific hardware of the experimental system is shown in Figure 6.

4.3. Test Results for and Analysis of the Automatic-Drilling-Identification Soft-Rock Interlayer Detector System in Drilling Rocks with Different Levels of Strength

Coal Mine Roadway Roof Rock

1. False roof: it is a thin rock stratum close to the coal seam and easy to collapse, at the same time, with the mining of coal. The thickness is generally $0.3 \sim 0.5 \mathrm{~m}$, which is mostly composed of shale, carbonaceous shale, etc.

2. Direct roof: it refers to the rock stratum directly above the false roof or coal seam (if there is no false roof), which often collapses with the withdrawal of support. The thickness is generally $1 \sim 2 \mathrm{~m}$, and it is mostly composed of mudstone, sandstone, siltstone, and other rocks that are easy to collapse.

3. Basic roof: also known as the main roof, it is a thick and hard rock layer located on the direct roof or directly on the coal seam (there is no direct roof and false roof at this time). It often hangs above the goaf for a period of time, and cannot collapse until it reaches a considerable area. It is usually composed of hard rocks such as sandstone, conglomerate, and limestone. The UCS parameters of different lithological rock formations on the roof of the roadway are shown in Table 1. 
Table 1. The roof rock parameters of coal mine roadway.

\begin{tabular}{cc}
\hline Material Type & UCS (MPa) \\
\hline fine sandstone & 57.3 \\
\hline mudstone & 37.5 \\
\hline sandy mudstone & 32.1 \\
\hline
\end{tabular}

The test was carried out using methods commonly employed for similar materials. The prepared C20 concrete was made from ordinary grade $32.5 \mathrm{R}$ cement, the C30 and C40 concrete were made from grade $42.5 \mathrm{R}$ Portland cement, and C50 was made from grade 52.5 R Portland cement. The proportions of similar materials are listed in Table 1. The maximum particle size of the stone was $15 \mathrm{~mm}$.

The hard rock was poured in a rectangular wooden mold box with a size of $150 \times 150 \times 150 \mathrm{~mm}$, with the rock strength as shown in Figure 7. A test block of $50 \times 50 \times 50 \mathrm{~mm}$ was simultaneously prepared. Each test block was consistent with the drilling test material. Then, a uniaxial compression test was carried out using a mechanical rock-servo testing machine. The results are shown in Table 2 (actual strength).

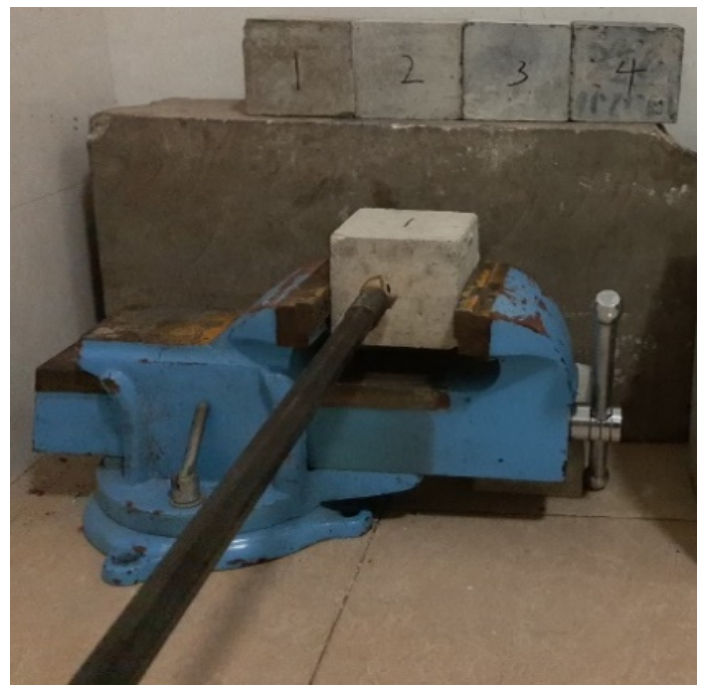

Figure 7. Concrete block.

Table 2. Ratios of similar materials.

\begin{tabular}{cclcc}
\hline \multirow{2}{*}{ Number } & Name & $\begin{array}{c}\text { Material Consumption per Cubic Meter of } \\
\text { Concrete } \mathbf{( k g / \mathbf { m } ^ { 3 } )}\end{array}$ & Theoretical Strength & Actual Strength \\
\hline 1 & C20 & Cement:water:Sand:Stone $=303: 185: 669: 1243$ & $25 \mathrm{MPa}$ & $21 \mathrm{MPa}$ \\
\hline 2 & C30 & Cement:water:Sand:Stone $=325: 185: 662: 1228$ & $30 \mathrm{MPa}$ & $29 \mathrm{MPa}$ \\
\hline 3 & C40 & Cement:water:Sand:Stone $=420: 185: 572: 1273$ & $40 \mathrm{MPa}$ & $39 \mathrm{MPa}$ \\
\hline 4 & C50 & Cement:water:Sand:Stone $=451: 185: 544: 1270$ & $50 \mathrm{MPa}$ & $51 \mathrm{MPa}$ \\
\hline
\end{tabular}

It can be seen from Figure 8 that, under the same pressure from the compressed air of the air compressor, when drilling four kinds of rocks with different strengths (C20, C30, C40, and C50) using an anchor drill, the force on the bit is almost the same, but the amplitude of the force on the bit, when drilling higher-strength rocks, is greater than that when drilling lower-strength rocks. 


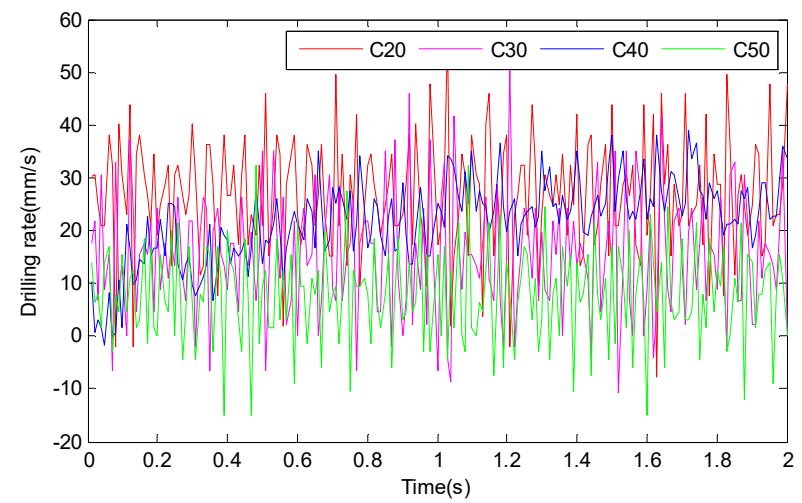

Figure 8. Drilling speed chart for bit drilling.

The torque and ROP values of the bit when drilling the high-strength rock and the bit when drilling the low-strength rock were very different, as shown in Figures 9-11. Moreover, the torque, ROP, and ROP amplitude of the rock with high bit-drilling strength were greater than those of the rock with low bit-drilling strength. In Figure 11, we find that the drilling speed signal noise is the largest.

As shown in Table 3, after calculating the average value of the force, torque, and ROP of the drill bit, when drilling rocks with four different levels of strength, and substituting these parameters into Formula (1), the specific fragmentation work of rocks with different strength levels can be calculated, as shown in Table 4. From this table, one can clearly distinguish the rocks with higher strength from the rocks with lower strength. The relationship between UCS (Y) and energy (X) in Table 3 is shown in Figure 12. The best coupling formula is:

$$
y=-0.0006 x^{2}+0.3177 x+11.153
$$

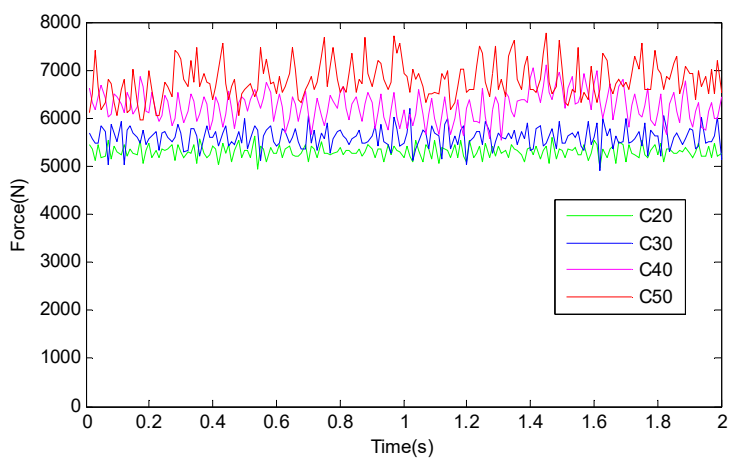

Figure 9. Drilling experiment of the drill bit.

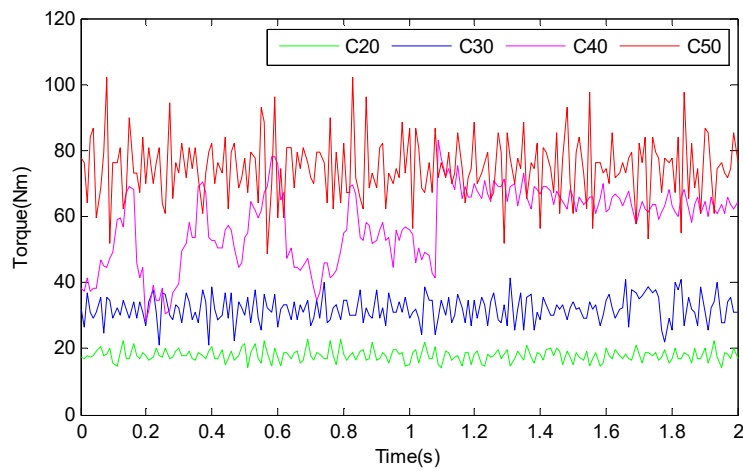

Figure 10. Torque diagram of bit drilling in the rock experiment. 


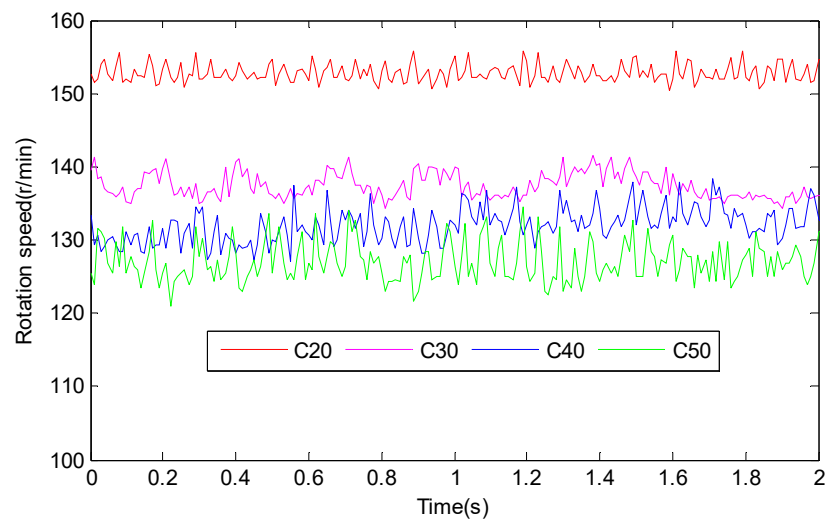

Figure 11. Speed chart of the rock drilling experiment.

Table 3. Bit input and output average parameters.

\begin{tabular}{ccccc}
\hline Name & Speed $(\mathbf{r} / \mathbf{m i n})$ & Drilling Rate $(\mathbf{m m} / \mathbf{s})$ & Torque $(\mathbf{N m})$ & Force $(\mathbf{k N})$ \\
\hline C20 & 152.3 & 26.7 & 20.1 & 5.4 \\
\hline C30 & 136.7 & 15.4 & 31.7 & 5.6 \\
\hline C40 & 122.7 & 10.5 & 52.2 & 5.9 \\
\hline C50 & 112.4 & 7.8 & 74.7 & 6.2 \\
\hline
\end{tabular}

Table 4. Comparison of specific fragmentation work of rocks and the uniaxial compressive strength of the experimental rock.

\begin{tabular}{cccc}
\hline Name & UCS/MPa & $\begin{array}{c}\text { The Energy Consumed by Rotational } \\
\text { Motion/(MJ/m } \mathbf{m}^{\mathbf{3}}\end{array}$ & $\begin{array}{c}\text { Predicted UCS } \\
\text { Coefficient }\end{array}$ \\
\hline C20 & $21 \mathrm{MPa}$ & 36.68 & 1.75 \\
\hline C30 & $29 \mathrm{MPa}$ & 57.05 & 1.97 \\
\hline C40 & $39 \mathrm{MPa}$ & 113.39 & 2.91 \\
\hline C50 & $51 \mathrm{MPa}$ & 192.46 & 3.77 \\
\hline
\end{tabular}

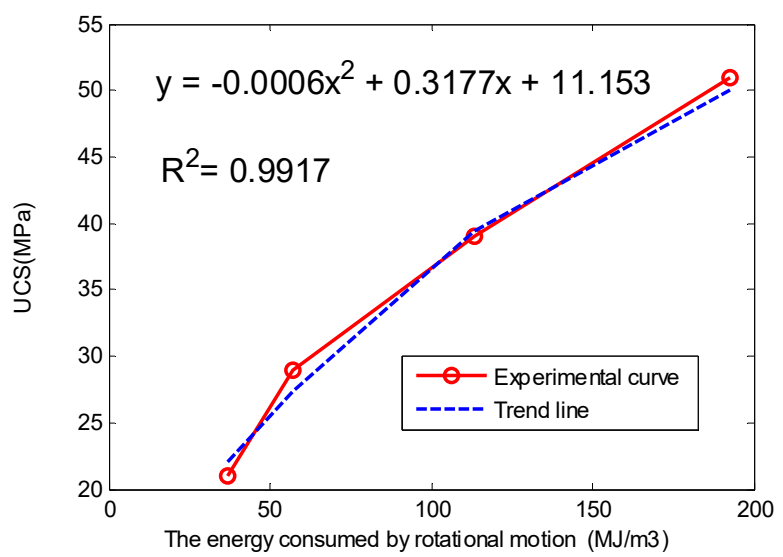

Figure 12. The graph from Table 3 of UCS (Y) vs Energy (X).

\subsection{Preparation of Similar Simulated Roof Strata}

Because rock is difficult to collect, the application of a simulation using similar materials was proposed. Similar-material simulations are an important element of scientific research. Such materials are made in a lab according to the similarity principle, based on a prototype model, with the help of the instrument's mechanical parameters and their 
distribution inside the observation model. We used the results from studying the model to determine the prototype's applicability and the pressure-distribution law of the rock-mass mechanical phenomenon. This process can help solve practical problems in engineering rock-mass production. This research method has the advantages of being intuitive, simple, economical, rapid, and requiring only a short experimental period. In this experiment, it was possible to study the spatial and temporal distribution and variation of rock stress, as well as the support pressure near the roadway roof, and the influence of some parameters on rock-mass pressure by fixing certain parameters, and changing others, based on the situation, which would be difficult to achieve under field conditions.

A similar simulated roof rock was prepared using Portland cement No. 52.5 (R). The maximum size of the pebbles was $15 \mathrm{~mm}$, and the similar materials were arranged, as shown in Table 5 . The hard rock was poured into a rectangular wooden mold box with a size of $150 \times 150 \times 150 \mathrm{~mm}$, as shown in Figure 13 .

Table 5. Similar material ratios.

\begin{tabular}{ccccc}
\hline Order & Definition & $\begin{array}{c}\text { Proportion of Materials Used per } \\
\left.\text { Cubic Meter of Concrete } \mathbf{( k g} / \mathbf{m}^{3}\right)\end{array}$ & $\begin{array}{c}\text { Theoretical } \\
\text { Strength }\end{array}$ & $\begin{array}{c}\text { Actual } \\
\text { Strength }\end{array}$ \\
\hline 1 & C40 concrete & $\begin{array}{c}\text { cement:river sand:stone:water }= \\
\text { 405:180:650:1205 }\end{array}$ & $40 \mathrm{MPa}$ & $39 \mathrm{MPa}$ \\
\hline 2 & C60 concrete & $\begin{array}{c}\text { cement:river sand:stone:water }= \\
\text { 525:180:530:1250 }\end{array}$ & $60 \mathrm{MPa}$ & $59 \mathrm{MPa}$ \\
\hline
\end{tabular}

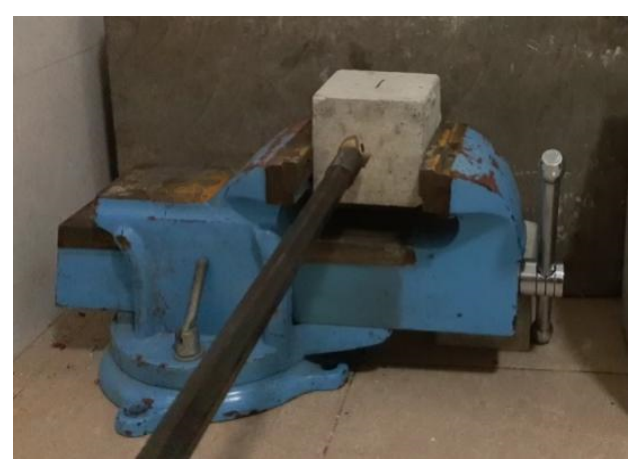

Figure 13. The similar material to roof rock.

The $50 \times 50 \times 50 \mathrm{~mm}$ test blocks were prepared at the same time, all of which were consistent with the drilling test materials. The UCS test was then carried out. A servo testing machine for rock mechanics was used in the experiment, and the results are shown in Table 4.

\section{Experimental Study on the Lithology Detection of a Roof While Drilling}

5.1. The Test Procedure for Detecting the Lithology of a Roof While Drilling

(1) Firmly connect the pneumatic bolt machine and compressed air source with the pipe. Connect the water supply and power supply lines to the bolt machine; then, power the compressed air source, and turn on the air compressor.

(2) Place the anchor drill horizontally in the set hole position on the ground and install the drill pipe, connecting the sleeve and bit.

(3) Connect each amplifier, data acquisition card, and stabilized voltage supply, according to the requirements of the wiring diagram.

(4) Turn on the DC-stabilized power supply to provide $+24 \mathrm{~V}$ direct current to the transmitter, start the computer, open the LabVIEW program, and debug.

(5) Supply water pressure and power to the drill and start drilling. 


\subsection{The Experimental Test Results and Analysis of Roof Lithology Detection While Drilling}

An NI USB-6009 data acquisition card was used in this experiment to collect data. To ensure the maximum rotation speed for the pneumatic motor of the bolt drill, we performed a loading experiment on the bolt drill.

When the motor was loaded to a certain value, the output speed of the motor became half of its maximum speed, and the motor output power was the largest. Using the power characteristic curve of the pneumatic motor, the power output of the pneumatic motor was maximum. According to Formula (1), the drilling speed output of the roof bolter was also maximum. Next, we adjusted the opening degree of the pneumatic motor and the leg valve of the pneumatic anchor drill from $0 \%$ to $100 \%$, and we controlled the data of the rotation speed and movement of the pneumatic motor within the error range. When drilling rocks with different UCS values (C40, C60), we found that the power falls on the curve of the rotation speed and the moment of the pneumatic motor, as shown in Figure 14. We also found that these data landed to the right of the parabolic line. The pneumatic anchor drill-leg pressure and pneumatic-motor output power do not match, making the pneumatic motor unable to achieve its maximum power. Due to the inadequate thrust of the pneumatic-leg pneumatic-motor, the output power could not reach its maximum, and the drilled hard-rock leg pressure was greater than that of the drilled soft-rock leg.

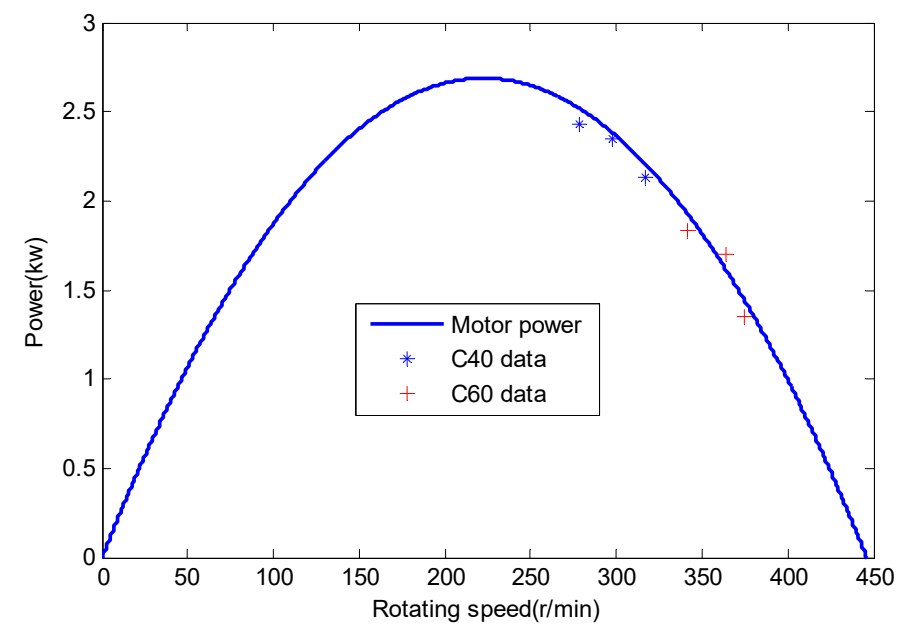

Figure 14. Curve of the rotation speed and torque of the pneumatic motor.

Since the thrust of the pneumatic leg cannot be increased arbitrarily, it must be matched with the actual situation. If the increase is too great, the output power of the pneumatic motor will decrease instead. To increase the output power of the pneumatic motor, and thus improve the drilling speed, an SMC COMPANY VBA booster valve model VBA43A-04 was installed in the system to improve the thrust of the leg.

As shown in Figure 15 (the internal structure diagram of the VBA and the structure principle of the SMC booster valve), the input air pressure was divided into two types: one that opens the one-way valve and fills booster rooms A and B of the small cylinder, as well as another that inflates driving room $B$ of the large cylinder through the pressure regulating valve, reversing valve, and the exhaust of driving room A. In this way, the large piston moves to the left, thereby driving the small piston to also move to the left, pressurizing small cylinder Chamber B, and opening the one-way valve to send high-pressure gas from the outlet. The small piston then moves to the end to switch the reversing valve, followed by the inlet of drive chamber $\mathrm{A}$ and the exhaust of drive chamber $\mathrm{B}$. Then, the large piston moves in reverse, chamber A is pressurized, the check valve is opened, and high-pressure gas continues to be sent from the outlet. This action can be repeated to obtain a continuous output of high pressure gas from the outlet. Further, outlet pressure feedback to the pressure-regulating valve can enable the outlet pressure to automatically maintain a certain value. When the outlet pressure must be changed, the hand wheel can be adjusted, 
and the outlet pressure can be set arbitrarily within the boost-ratio range. If the outlet feedback pressure is balanced with the spring force of the pressure-regulating valve, the booster valve will stop running and no longer output the flow.

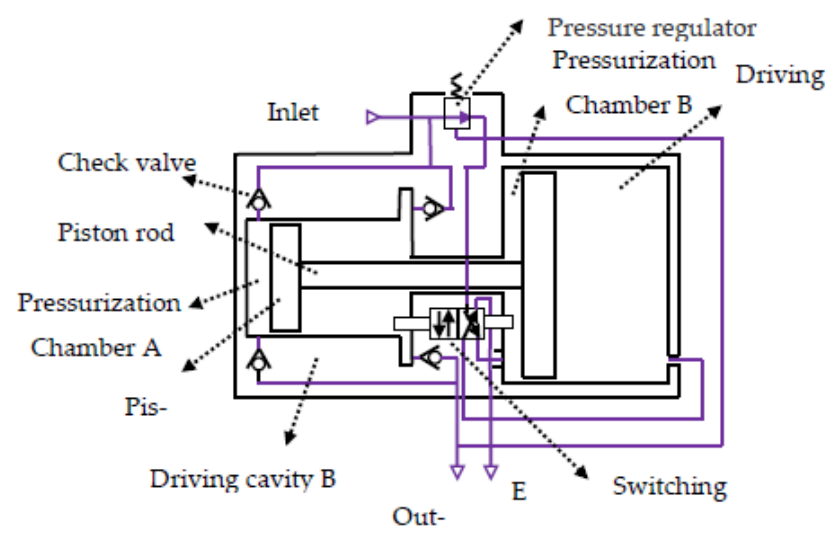

Figure 15. The internal structure of the SMC VBA pressurized valve.

As shown in Figure 16, the power of the pneumatic motor was increased by applying the booster valve and increasing the leg thrust appropriately throughout the test. By testing the drilling speed, we found that the power of the pneumatic motor was linearly related to the drilling speed, as shown in Figure 17, which demonstrated that increasing the motor power can improve the drilling speed, thereby providing a possible method for optimizing drilling speed.

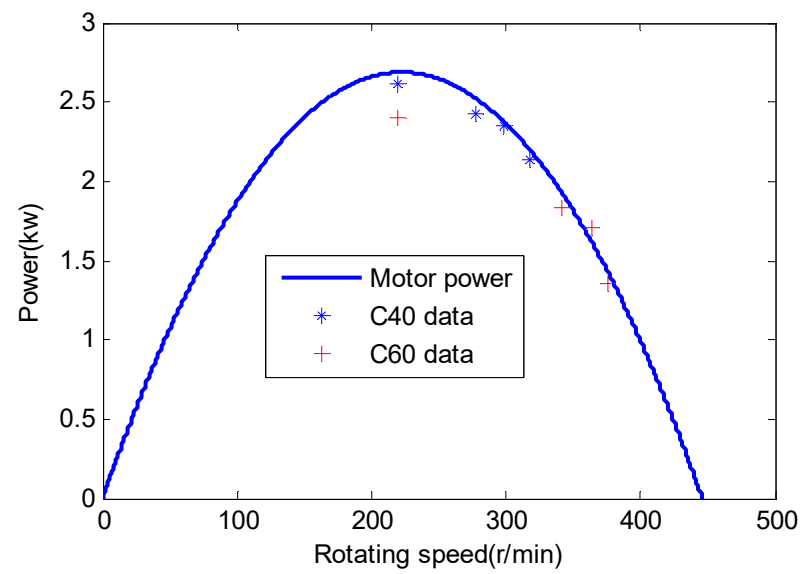

Figure 16. The power curve of the pneumatic motor after increasing the thrust of the leg.

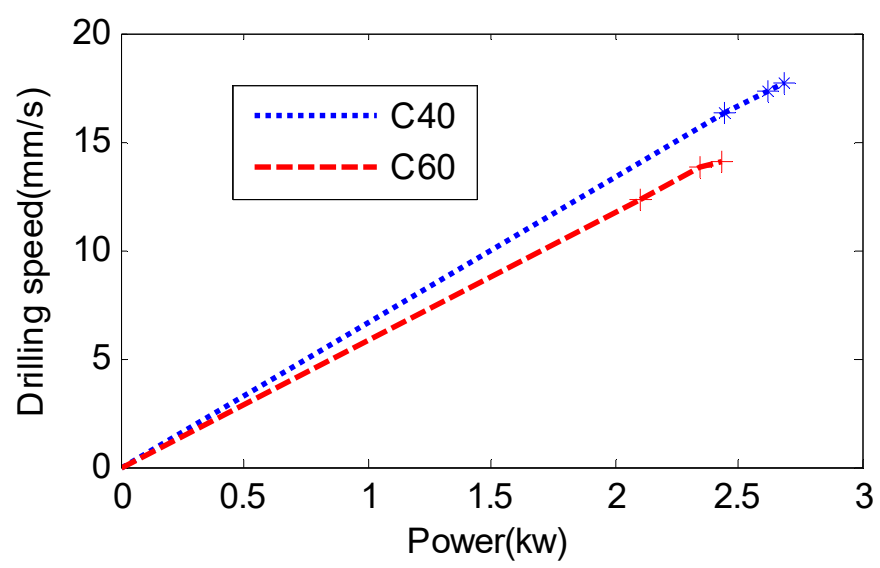

Figure 17. Curve of the power, and drilling rate, of the pneumatic motor. 


\section{Conclusions}

The present research found that the maximum output power of the pneumatic motor was related to the unconfined compressive strength of different rocks and the support-leg pressure. The leg pressure of the pneumatic anchor drill did not match the output power of the pneumatic motor, which made the pneumatic motor unable to reach its maximum power point. Because the thrust of the pneumatic support leg was insufficient, the output power of the pneumatic motor could not reach its maximum, and the pressure of the hard-rock leg was less than that of the soft-rock leg.

To improve the output power of the pneumatic motor and increase the drilling speed, we applied and installed a pressure valve in the system. Through the test of the drilling speed, we found that the power of the pneumatic motor was linearly related to the drilling speed. The test demonstrated that the efficiency of the method for improving the motor power and drilling speed could be improved.

According to the theory of the unconfined compressive strength of roof rock, which can be determined by detecting the specific work of broken rock, a certain type of motor speed and torque was adopted in the pneumatic system to detect the drilling of the pneumatic bolt. A new system for identifying the strength of roadway roof rock was proposed based on the variation in the leg-cylinder force and drilling speed.

A mathematical model of the drilling power output was also derived. Using this model, the drilling machine was able to optimize the drilling speed, and the output power curve of the pneumatic motor was a parabola. The maximum value of the parabola was found to optimize the drilling speed of the drilling machine. However, the UCS values were different between different rocks, and the maximum output power of the pneumatic motor was also different.

The present study found that the maximum pneumatic motor's output power had a relationship with the different rock UCS and leg-pressure values. The pressure of the supporting leg of the pneumatic bolt drill did not match the output power of the pneumatic motor, which was unable to reach its maximum power point. This occurred because the thrust of the pneumatic leg was insufficient for the output power of the pneumatic motor to reach its maximum. Moreover, the pressure of the drilled hard-rock leg was less than that of the drilled soft-rock leg.

To improve the output power of the pneumatic motor and the drilling speed, a booster valve was designed and installed in the system. By testing the drilling speed, we found that the power of the pneumatic motor was linearly related to the drilling speed, which demonstrated that the effectiveness of the drilling speed method could be improved by increasing the motor power.

When the air pressure is $0.5 \mathrm{MPa}$, the average power of the C40 and C60 rock is 2.3 and $1.6 \mathrm{~kW}$, respectively. All power values fell to the right of the parabola center line, which indicates that the leg pressure of the pneumatic roof-bolter did not match the output power of the pneumatic motor, making the pneumatic motor unable to reach its maximum power point. When the air pressure was increased to $0.6 \mathrm{MPa}$ by using the booster valve, the maximum power of the roof-bolter drilling C40 rock reached $2.5 \mathrm{~kW}$, and the maximum power of the roof-bolter, when drilling C60 rock, almost reached $2.4 \mathrm{~kW}$. Through this method, the drilling rates of the C40 rock and C 60 rock increased by $12 \%$ and $15 \%$, respectively, and the work efficiency was obviously improved.

Due to the limitation of experimental conditions, we use similar materials to do experiments, the properties of similar materials are relatively stable, and the results are also satisfactory. Measurement while drilling is affected by many factors, and we will consider these factors in our follow-up research.

Author Contributions: All authors discussed and agreed upon the idea and made scientific contributions. G.Y. and G.M. conceived the original idea and designed the experiments; G.Y. and X.F. conducted the experiments; G.Y. wrote the paper; G.M. is the advisor of G.Y., provided the funding, and revised the paper. Q.H. guide and modify research ideas, and complete manuscript editing and 
review. Y.N. article writing and drawing. All authors have read and agreed to the published version of the manuscript.

Funding: This research was funded by the National Key Research and Development Program of China (Grant number 2016YFC0600900).

Institutional Review Board Statement: Not applicable.

Informed Consent Statement: Not applicable.

Data Availability Statement: The data that support the findings of this study are available within the article. Other data are available from the corresponding author upon reasonable request.

Acknowledgments: The authors would like to thank all sources of funding.

Conflicts of Interest: The authors declare no conflict of interest.

\section{Notation}

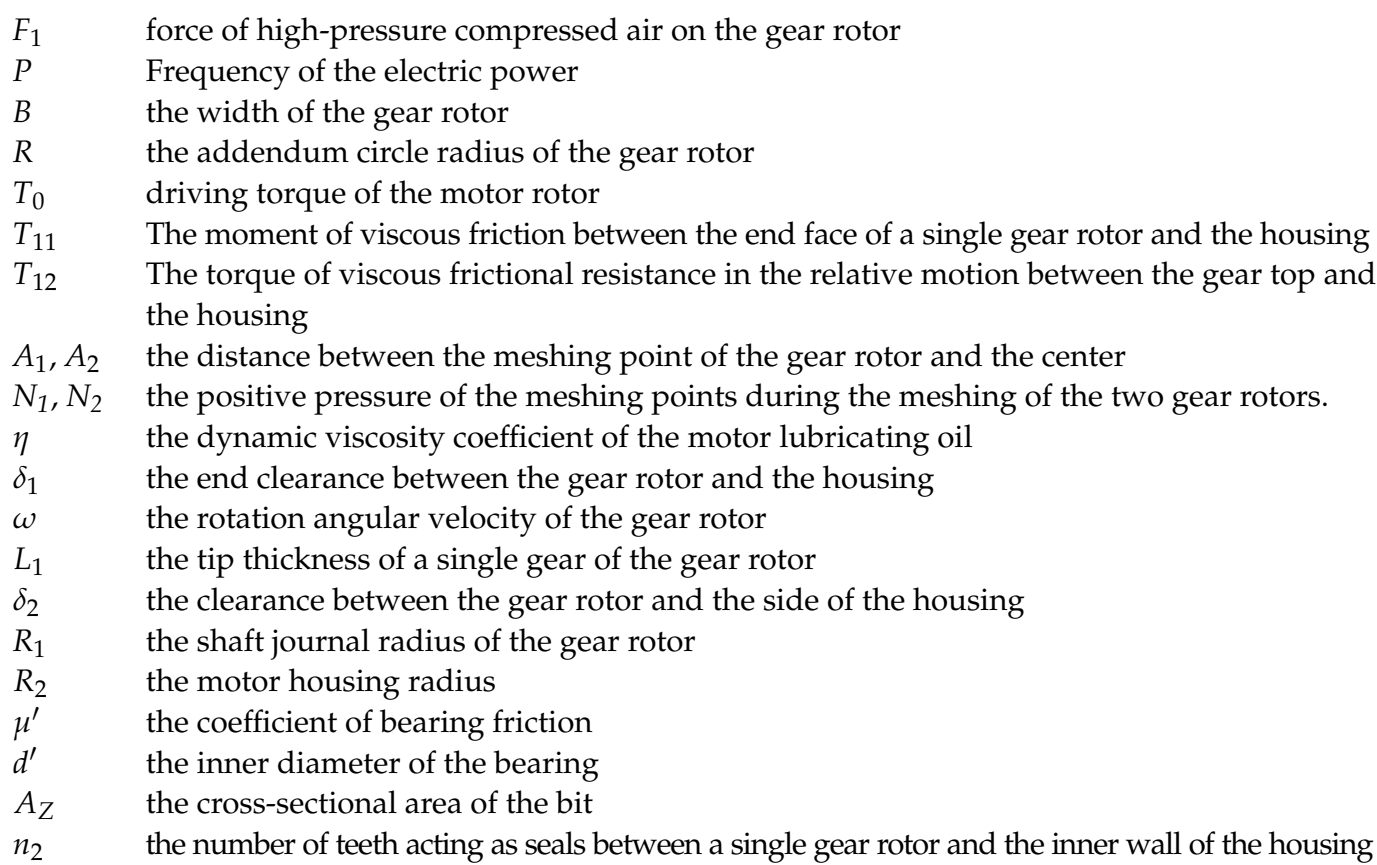

\section{References}

1. Gao, J. System Model of Coal Industry Layout Optimization under Resource and Environment Constraints. Ph.D. Thesis, China University of Mining and Technology, Beijing, China, April 2015.

2. Wang, J. Analysis on the influence of unconfined compressive strength of floor rock on the stability of surrounding rock. Coal Mine Mod. 2019, 5, 86-89.

3. Guo, S. Study on the Vibration Response Characteristics of Broken Roof Rock in Coal Roadway. Open Fuels Energy Sci. J. 2016, 9 , 92-101. [CrossRef]

4. Khorzoughi, M.B.; Hall, R.; Apel, D. Rock fracture density characterization using measurement while drilling (MWD) techniques. Int. J. Min. Sci. Technol. 2018, 28, 24-29. [CrossRef]

5. Sun, Y.; Li, X.S.; Guo, H. Influence of Roof Rock Thickness on the Failure Probability of Thermally Stable Diamond Composite Rock Cutting Tips. Key Eng. Mater. 2021, 878, 98-103. [CrossRef]

6. Howarth, D.F.; Rowlands, J.C. Quantitative assessment of rock texture and correlation with drill-ability and strength properties. Rock Mech. Rock Eng. 1987, 20, 57-85. [CrossRef]

7. Teale, R. The concept of specific energy in rock drilling. Int. J. Rock Mech. Min. Sci. Geomech. Abstr. 1965, 2, 245-250. [CrossRef]

8. Tiryaki, B.; Dikmen, A.C. Effects of Rock Properties on Specific Cutting Energy in Linear Cutting of Sandstones by Picks. Rock Mech. Rock Eng. 2006, 39, 89-120. [CrossRef]

9. Beattie, N. Monitoring-While-Drilling for Open-Pit Mining in a Hard Rock Environment: An Investigation of Pattern Recognition Techniques Applied to Rock Identification. Master's Thesis, Queen's University, Kingston, ON, Canada, April 2009.

10. Liu, S.; Fu, M.; Zhang, H.; Yue, J. Vibration mechanism and characteristic analysis of drill pipe in coal roadway roof anchor hole drilling. J. China Univ. Min. Technol. 2016, 45, 893-900. 
11. Gao, S. Identification Method of Roof Strata in Coal Roadway Based on Vibration Characteristics While Drilling. Ph.D. Thesis, China University of Mining and Technology, Beijing, China, March 2017.

12. Tan, Z.; Cai, M.; Yue, Z.; Tan, G.; Li, Z. Theory and method of formation interface identification based on rock drillability index. J. Beijing Univ. Sci. Technol. 2006, 9, 803-807.

13. Chen, J.; Deng, H.; Gao, M.; Cheng, Y.; Wang, C. Study on identification of roof strata while drilling in tunneling roadway. J. Min. Saf. Eng. 2016, 33, 271-277.

14. Li, X. Experimental Study on Drilling Characteristics of Anchor Hole in Coal Roadway Roof. Ph.D. Thesis, Henan Polytechnic University, Henan, China, April 2015.

15. Li, Z.; Kenichi, I.; Tomita, S.; Iguchi, S. Prediction of Rock Strength from Rotary Drill Performance Parameters. In Proceedings of the 2009 Korea-Japan Joint Symposium on Rock Engineering, Suwon, Korea, 22-23 October 2009; pp. 57-65.

16. Li, Z.; Itakura, K.I. An analytical drilling model of drag bits for evaluation of rock strength. Soils Found. 2012, 52, 216-227. [CrossRef]

17. Yenice, H.; Zdoan, M.V.; Zfrat, M.K. A Sampling Study on Rock Properties Affecting Drilling Rate Index (DRI). J. Afr. Earth Sci. 2018, 1-8. [CrossRef]

18. Yetkin, M.E.; Ozfirat, M.K.; Yenice, H.; Simsir, F.; Kahraman, B. Examining the relation between rock mass cuttability index and rock drilling properties. J. Afr. Earth Sci. 2016, 124, 151-158. [CrossRef]

19. Da Hl, F.; Bruland, A.; Jakobsen, P.D.; Nilsen, B.; Grov, E. Classifications of properties influencing the drillability of rocks, based on the NTNU/SINTEF test method. Tunn. Undergr. Space Technol. Inc. Trenchless Technol. 2012, 28, 150-158. [CrossRef]

20. Ozfirat, M.K.; Yenice, H.; Simir, F.; Yarali, O. A new approach to rock brittleness and its usability at prediction of drillability. J. Afr. Earth Sci. 2016, 119, 94-101. [CrossRef]

21. Ju, M.; Wang, D.; Shi, J.; Li, J.; Yao, Q.; Li, X. Physical and numerical investigations of bedding adhesion strength on stratified rock roof fracture with longwall coal mining. Geomech. Geophys. Geo-Energy Geo-Resour. 2021, 7, 1-31.

22. Ma, B.; Hu, Z.; Chen, X.; Chen, L.; Wei, D. Mechanical Properties of Sandstone Roof and Surrounding-Rock Control of Mining Roadways Subject to Reservoir Water Disturbance. Adv. Civ. Eng. 2021, 7, 1-16.

23. Huang, Z.; Zhang, L.; Ma, Z. Study on the Mechanical Relationship among the Backfilling Mining Support, Roof Rock Beam, and Gangue Filling Body in Comprehensive Mechanized Filling Mining Process. Adv. Civ. Eng. 2020, 4, 1-15. [CrossRef]

24. Ma, Q.; Tan, Y.; Liu, X.; Gu, Q.; Li, X. Effect of coal thicknesses on energy evolution characteristics of roof rock-coal-floor rock sandwich composite structure and its damage constitutive model. Compos. Part B Eng. 2020, 198, 108086. [CrossRef]

25. Tao, Z.; Luo, S.; Wu, D.; Qiao, Y.; Zhao, G.; Meng, Z. Stability Evaluation of Deformation (Denudation) of Yuanjue Rock Cave Roof Based on Multisource Monitoring. Shock Vib. 2020, 1, 1-12. 